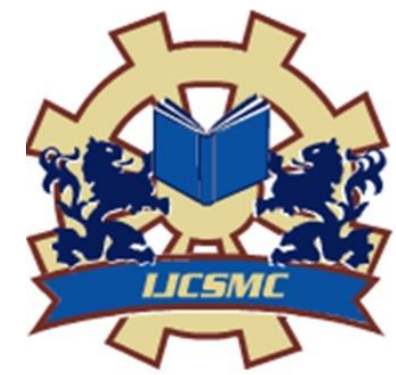

A Monthly Journal of Computer Science and Information Technology

IJCSMC, Vol. 10, Issue. 2, February 2021, pg.50-53

\title{
Emotion Based Music Player
}

Agrawal Abhishek Pradeep ${ }^{1}$; Kalyani Bhagwan Vispute ${ }^{2}$; Vaishnav Sham Bhavsar ${ }^{3}$ Sagar Prakash Wadile ; Prof. Vishakha N. Pawar $^{5}$ ${ }^{1,2,3,4}$ Students, Department of Computer Engineering, Guru Gobind Singh Polytechnic, Indira Nagar, Nashik, India

${ }^{5}$ Lecturer, Department of Computer Engineering, Guru Gobind Singh polytechnic, Indira Nagar, Nashik, India DOI: 10.47760/ijesmc.2021.v10i02.007

\begin{abstract}
Recent studies confirm that humans respond and react to music and that music has a high impact on person's brain activity. Many people likes to listen music often. Many of people have hobby to listen music. So music plays an important role in one's life. People react to music by their emotions. People tend to listen to music based on their mood and interests. This project focuses on creating an application to suggest songs for user based on their emotions by differentiating different kind of moods. This application is only based on moods and emotion depending on user's mood. For developing this application we are using Android Studio. This application is framed friendly to user.
\end{abstract} Keywords: Music, Categorization, Recommendation, Android

\section{INTRODUCTION PROJECT DESCRIPTION}

Music is an important medium of life. Everyone likes to listen music but what if we made more easier for user to listen music by differentiating there mood? Now a days we have grown up with advanced technology. Many mobile application have came up with many function like emotion capturing with artificial intelligence, gesture, sleeper time, lyrics , shuffle play and many more. This application is randomly similar that off but here we came up with new function called Emotion Based Music Player with many different Moods. Here user can select music list depending on their current emotion or we can also call as mood so after clicking to different types of mood a list of songs would be displayed. And user can also search their favourite songs by searching in-search tab. User can also create there playlist. This application is made for online as well as offline too. User can easily handle this application because many of us have been using different kind of music players day-by-day.

\section{Motivation and Problem statement}

Music listeners have tough time creating and segregating the play - list manually when they have hundreds of songs. It is also difficult to keep track of all the songs sometimes songs that are added and never used, wasting a lot of device memory and forcing the user to find and delete songs manually. User's have to manually select songs every time based on interest and mood. User's also have difficulty to re-organize and playing music when play-style varies. Currently in existing application, music is organized using playlist and different types of moods. When user will click to their current type of mood it might happen that they don ' $t$ like the play - list created by the developer because here developer is also playing the role of user so it's hard to define that's what kind of play -list user would like. Everyone have their own choice about them, contrast colour. This also become necessity to give choices about them dark, light, colourful. As a music lover I thought to give a effort less music player like speech to play music and more impressive function. A music player should be build in such a manner which satisfies user with perfect sound quality and many more option of improving bass . Many people like high bass, live, Custom, Rock Jazz, Electronic and many more types of effects in sound mode so it is challenging parts to provide all in equalizer.

\section{Problem Discussion}

Using traditional music players a user had to manually browse through his playlist and select songs that would soothe his mood and emotional . In today's world, and technology, various music players have been developed with features like fast forward, reverse, variable playback, streaming 
play back with multicast streams and including volume modulation, genre classification etc. Although these features satisfy the user's has to face the task of manually browsing through the play-list of songs and select songs based on his current mood and behaviour. For accessing this application user has to first login or sign-up. User can see various types of moods in Mood tab after login. Such as Chill, Romance, Energy Booster, many more. And when a user clicks on mood as per there choice list of songs would be displayed and user can enjoy their time by listing music. User can download as well as share there play-list. User can do search with music as well as artist also.

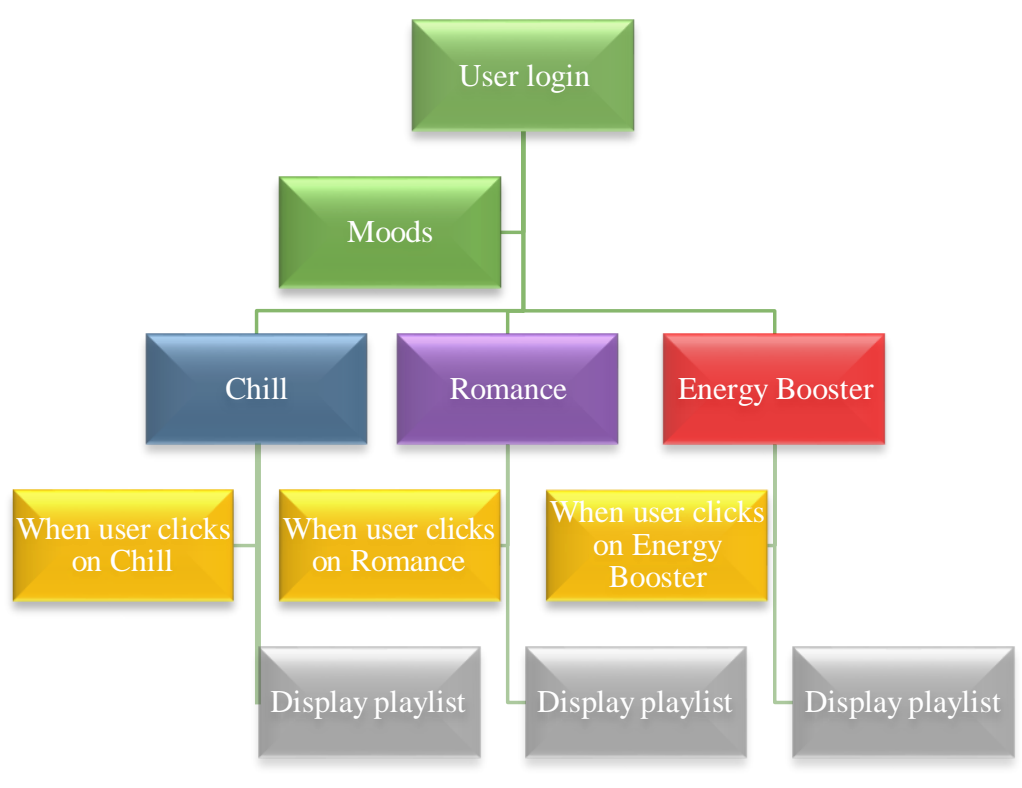

\section{Objective}

Project EMP [Emotion Based Music Player] is a novel approach which helps user to play the songs according to their emotion/mood. In android we can apply many features. This application is made for android users only from seventh version which is (Nought) and further more . Firstly user have to sign up or login to access the application and then can according search songs or by just clicking on moods user can also access songs play list. user can also access this application on desktop too. To access in desktop user need windows7 or further version. User can also upload his / her playlist from device. Also can download songs and also can share from our application. In this application dark as well as light theme are provided for user eye comfort. Users can boost their sound in equalizer. Our application does not contain any add because we have observed in many famous application they put add in middle and we get disturbed so just to make user happy we haven't collaborated with any type of article add. And we believe in equality so we haven't added any premium package this application is same for all user.

\section{Existing System}

We have came up with advanced technology where we can develop any type of apps. At present Spotify is the best music player where can listen only online music but can download songs in device. In spotify we get to see many feature like Recently played songs, Shows you might like, Your 2020 wrapped, Free Kicks, Popular playlists, Best of artist, Popular an trending. Here you can get premium to after paying online . User can make your playlist according to your favourite artist. Even you can create your profile, account. Best thing you get an Equalizer to control your music sound effects. User can connect another devices through Bluetooth and wifi. Here we get many buttons like shuffle, loop, next, previous, resume, stop, like button to add liked songs in liked playlist, Seek Bar, many more features are available in spotify music player which comes at the top in music player. Languages used at backend in Spotify is Python and other then JAVA, C ++, and C is used to make available in OS, macOS, Linux. Spotify is famous in world wide. Now a days in every music player this all features are common to see.

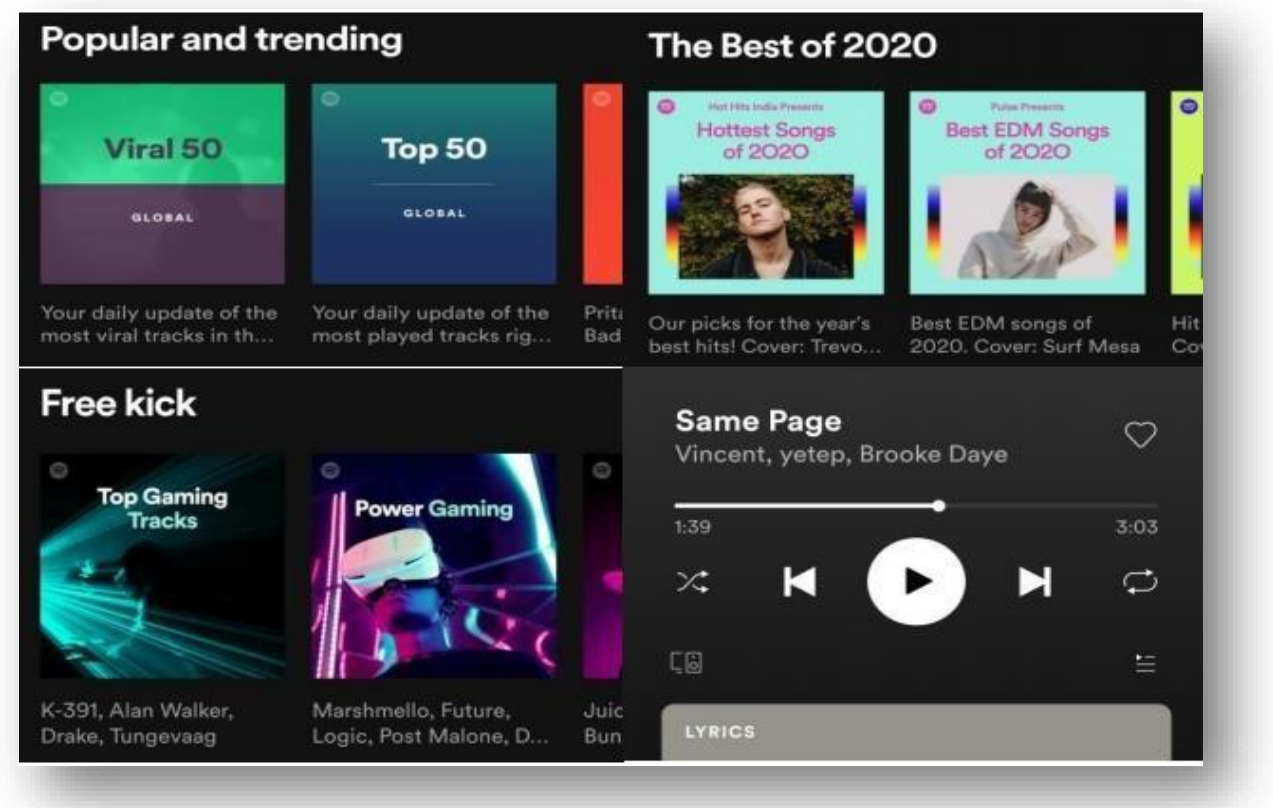

[ Spotify Music Player ] 


\section{Proposed System}

Here we have proposed an Emotion Based Music Player where user can play a song according to their mood and emotion. It aims to provide user preferred music with respect to their mood. Emotion based music player is an idea of giving an effortless mobile application where user can play song according to their present emotion or mood. After clicking to specific mood its recognized by inner code and accordingly play list is displayed. If you are a new user firstly you have to signup so you won't miss any update. For accessing desktop site user have to login . When this application starts it displays users play list and suggest new songs as well as suggest according to mood. When user plays song according to their mood it ask for up vote button if user denied it the song wont be added to play list and if user allow it then the song will be added in play list . If user don't like the song then they can downvote the song and then again new list will be suggested by application. And next song will be played automatically suggested by application or user can search specific music by song name or artists . User can download as well as share songs.

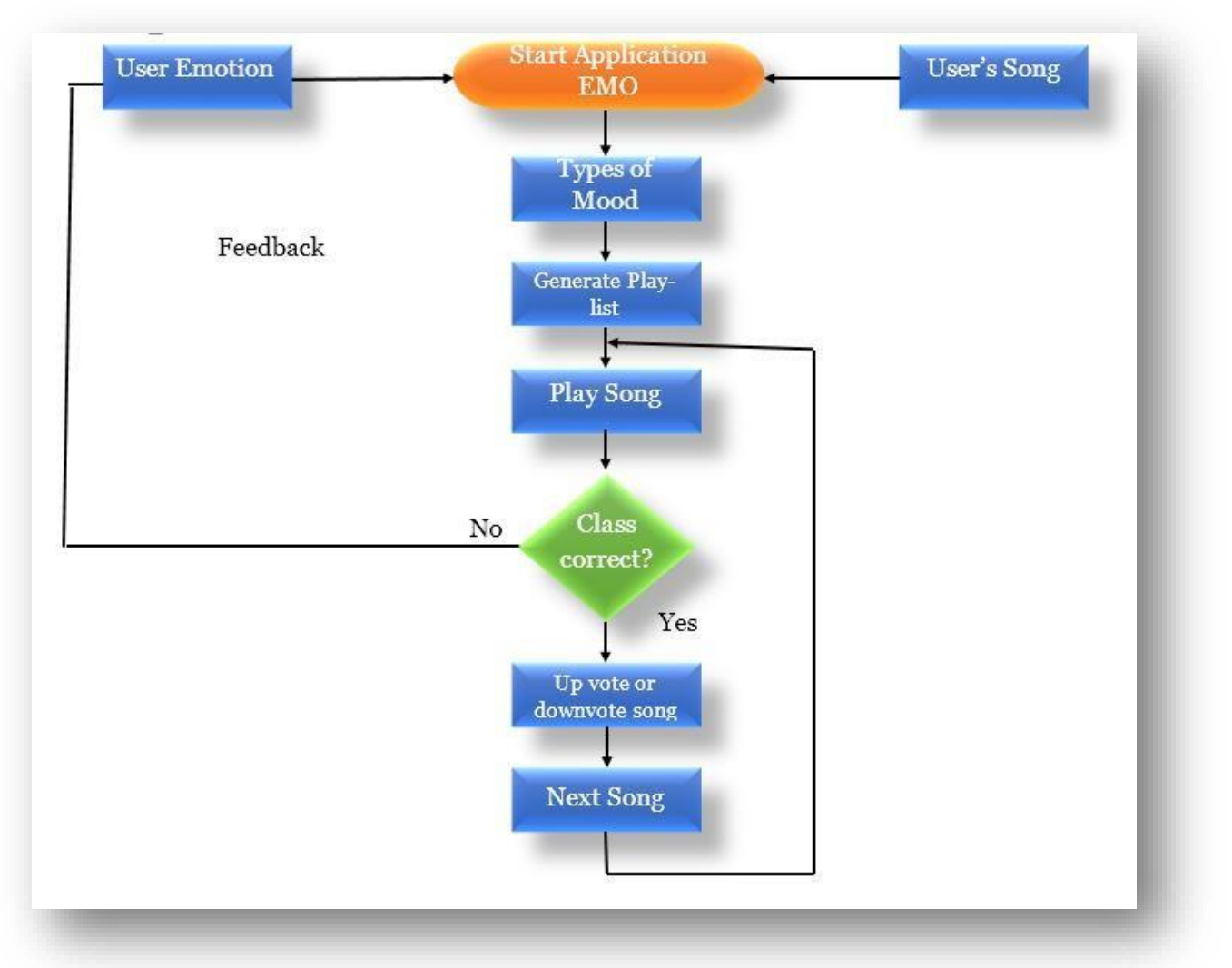

\section{REQUIREMENTS}

\section{HARDWARE REQUIRMENT}

Processor : - Intel Core i3. RAM : - 4 GB RAM.

Space Required : - 2GB.

\section{SOFTWARE REQUIREMNT}

Requirement deal with define software resource requirements and pre-requisites .That need to be installed on a computer to Provide optimal functioning of an application.

- Python2.0

- Android studio

\section{ADVANTAGES}

- The Emotion Based Music Player system will be of great advantage to the user looking for music based on there moods and emotional behaviour.

- It will help to reduce the searching time.

- User can play song effortlessly.

- Songs will be played according to the user's mood.

- User can also download songs from this application.

\section{CONCLUSION}

This Project has been developed to give us a great advancement in the field of human behaviour. In this project we have used more than 9 moods which can be ordinarily found in humans. Emotion Based Music Player fulfil to sort out music based on moods. Our main aim is to consume user's time and to satisfy them. We have designed this application in such a manner that it can run in mobile [ Android ] as well as desktop [ Windows ]. 


\section{APPLICATION}

- Plays songs according to user mood and emotions.

- Act as plugins for website.

- Recommended for YouTube.

\section{REFERENCES}

[1]. S, P. J., Rajashree, S. M., S. H., \& .J, S. S. (2018). Review on Facial Expression Based Music Player. International Journal of Engineering Research \& Technology ( IJERT ), 6(15), 1-3.

[2]. Cherry, K. (2018). The 6 Types of Basic Emotions and Their Effect on Human Behavior. Retrieved from Very well Mind: https://www.verywellmind.com/about-us

[3]. Developer, A. (n.d.). Create an Android project. Retrieved from developers: https://developer.android.com/training/basics/firstapp/creating-project

[4]. ED, B. (2015). Hello, Android. In S. D. Pfalzer (Ed.), Hello, Android (Vol. 4, p. 319). Pragmatic Bookshelf.

[5]. H. P., Adarsh, .B, A. C., \& Kumar, V. A. (2018, April). Emotion Based Music Player. International Research Journal of Engineering and Technology ( IRJET ), 05(04), 1-6. 